and the intervention of his friends saved him from the carrying out of a death sentence; but these years left their mark on him.

In 1947 he was appointed to the new chair of crystallography in the University of Marburg and he threw himself with great energy into the teaching of the subject and into the building-up of an active research school. But he also gave much of his time to the work of the Society of Friends, of which he and his wife were members, and to efforts to promote international understanding. His presence at conferences was the more valued because of his great gift for languages; if a new language interested him, he learnt it.

The statement put out by the Rector and Senate of the University of Marburg says of him: "Carl Hermann was a man of absoluto integrity, and of kindness to others which had no limit. For many years he was a member of the Diseiplinary Court of the University and it was always he who tried to understand and to excuse the defendant ...".

He is not likely to be forgotten, for he has left many friends.

Kathleen Lonsdale

\section{Prof. E. Taylor Jones}

THe death on September 29 of Prof. Edward Taylor Jones at the age of eighty-eight will have been noted with deep regret by the many who benefited from his unique qualities both as a teacher and research supervisor. His own education followed a pattern that was familiar at the turn of the century. His studies at University College, Bangor, and the University of Berlin wore followed by a time as professor of physics at Bangor and a long period as professor of natural philosophy in the University of Grasgow, a period prolonged by the advent of war in 1939. His interests throughout his life extended over a wide field of physics and he seemed, in fact, to be equally interested in physics and in electrical engineering. Thus, his earlier researches were in the classical field of electromagnetism with special reference to the mechanism of oscillatory devices such as the singing arc, the induction coil, the Tesla coil, and the magneto.

Research into the behaviour of the induction coil may well have led to his very early attack on a variety of problems in electron diffraction. He was greatly excited by the elegant de Broglie approach to wave mechanics and soon followed the lead given by G. P. Thomson at the University of Aberdeen in his famous work on electron diffraction. This was a notable switch in interest and could have resulted in a greater volume of original work but for the limitations of means and research students of that time. Nevertheless, on average he supervised the work of some five research students throughout his active career. I myself realized, as one of his research students, that Taylor Jones made many fruitful suggestions while never stultifying the initiative of members of his team. Ho preferred to play the part of adviser and in this he gave freely of his store of knowledge.

He will doubtless be remembered by most as an inspired teacher of the very large ordinary classes. These seemed to fascinate him. He took great pains to make his courses lively and even at times hilarious, obviously believing that above all interest must be generated. His extremely expert clowning in some of his demonstrations made it inconceivable that an understanding of the fundamentals should be beyond any student. In spite of this unique approach to his ordinary classes there was considerable discipline in his handling of classes of more than two hundred students. With the advanced classes he was content to follow more orthodox patterns of instruction. He must have roused within many a life-long interest in physics by his vivid proof that science could be fun.

Prof. Taylor Jones had many publications to his credit and the list of these shows his versatility and widely ranging interests. Physics made startling advances throughout his life and he was excited by many of them. He did not confine his research interests closely and he never looked with favour on team-work. In this respect he belonged with the individualists of his earlier period. Those who knew him as a friend realized how fully he enjoyed his life spent in physical science.

S. C. Curran

\section{Dr. Madeline Kerr}

IT was with deep regret that the colleagues and friends of Dr. Madeline Kerr learned of her death on August 22, a few months after she had resigned from her post of senior lecturer in social science in the University of Liverpool because of ill-health.

Dr. Kerr was primarily a social psychologist, but the richness and variety of her interests in the cultural process took her work into the sociological and anthropological fields. Dr. Kerr graduated at Manchester and, after working in the Psychological Service of the Liverpool Education Committee, returned to take up the Knight fellowship in psychological medicine. At Manchester she was influenced by Prof. T. H. Pear and retained an interest in the interaction of social status and personality traits. From Manchester she went to London, where she took her doctorate and worked with Prof. Lancelot Hogben. She then joined Prof. Susan Stebbing to teach psychology in the Department of Philosophy at Bedford College. She was a great admirer of Susan Stebbing and this was reflected in the logical austerity of her seminar teaching.

In 1947 Dr. Kerr was given leave of absence to act as social psychologist to the West Indian Social Survey, where she organized a programme of psycho. logical testing. In the West Indies, Dr. Kerr found an environment in which her interests in the graphic and plastic arts and in music combined with her scientific interests to make her immediately acceptable to the subjects of her study, and she made lasting friendships with mombers of all classes in West Indian society from simple peasants to members of the Government. Some of the findings of her work were published in Personality and Conflict in Jamaica (1952).

On her return to England it was natural that she should join Prof. T. S. Simey, who had also worked in the West Indies, in the Department of Social Science of the University of Liverpool. Here she continued her intensive investigation on families, and in 1958 published The People of Ship Street, which described the existence of a matriarchal society in a working-class area of Liverpool.

In Liverpool she devoted most of her energies and her great enthusiasm to her students, for whom nothing was too much trouble and with whom she made close and enduring friendships. She will be greatly missed. 